\title{
Especial nurse call system for ICU patient
}

\section{-Nurse call system}

\author{
Soheila Mojdeh ${ }^{1}$, Mohammad Mehdi Nadi ${ }^{2}$, Kasra Gordiz ${ }^{3}$, Gholamreza Khalili $^{4^{*}}$, Alireza Sadri ${ }^{5}$ \\ ${ }^{1}$ Nursing and Midwifery School, Isfahan University of Medical Sciences, Isfahan, Iran \\ ${ }^{2}$ Electrical Engineering, Isfahan University of Technology, Isfahan, Iran \\ ${ }^{3}$ Computer Engineering Student, Islamic Azad University Khorasgan (Isfahan) Branch, Isfahan, Iran \\ ${ }^{4}$ Department of Anesthesiology, School of Medicine, Isfahan University of Medical Sciences, Isfahan, Iran \\ ${ }^{5}$ Medical Engineering, School of Technology and Health, KTH University, Stockholm, Sweden \\ Email: mojdeh@mail.mui.ac.ir, mmnabi@gmail.mui.ac.ir, ka gordiz@yahoo.com, ${ }^{*}$ Khalili@mad.mui.ac.ir \\ Received 19 May 2013; revised 19 June 2013; accepted 7 July 2013 \\ Copyright (C) 2013 Soheila Mojdeh et al. This is an open access article distributed under the Creative Commons Attribution License, \\ which permits unrestricted use, distribution, and reproduction in any medium, provided the original work is properly cited.
}

\section{ABSTRACT}

Introduction: The ring system is one of the devices that are necessary for patients in hospital. Patients can use it in emergencies and call nurses for help. Patients who have a tracheal tube cannot make the simplest requests, and they do not have verbal communication due to tracheal tube or tracheostomy tube. According to surveys, patients' survival is $55.5 \%$ in intensive care unit (ICU). They experience severe stressful conditions. This project is designed to solve communicational problems for ICU patients. We have developed and successfully tested a new moveable “nurse call system" for ICU patient. Material Methods: this is an interventional study. Regarding the main goal of this project, it seems that the best design for "nurse call system" is horizontal panels. The Panel of device contains a touchable board, which consists of symbols that allow patients to select them despite of their physical limitation. When patient touches any symbol, the message will be sent and heard by the nurse and the patient as well, so the patient will be sure that the massages is received properly. A notepad device will be used on which patients are able to write too. It is finger touch, and has virtual keywords in both Persian and English alphabets. The voice messages and other data will be transmitted to the computer in central nurse station by a wireless accesses point. In this study, we evaluated the viewpoint of nurses and patients who have used this device. Results: 40 questionnaires were distributed, but 30 cases were collected. Results showed that $26.7 \%$ (8 cases) were men, $73.3 \%$ ( 22 cases) women. $26.7 \%$ ( 23 cases) were nurses, $6.7 \%$ (2 cases) doctor, $6.7 \%$ ( 2 cases) nurse assistant. $33.3 \%$ ( 9 cases) were in the morning shift,

${ }^{*}$ Corresponding author.
66.7\% (21 cases) worked in other shifts. About patient $60 \%$ (6 cases) were men, $40 \%$ (4 cases) women and in $98 \%$ comments were completely compliant and device was full consent. Conclusion: The Nurse Call system caused patients' satisfaction. In addition, this device resolved many problems of patients and made it possible to have active communication with them.

Keywords: ICU Patient; Nurse Call System

\section{INTRODUCTION}

Nurse Call System is one of the essential things that patients need. Usually each patient's bed has a buzzer system. Nurses and other health personnel immediately attend the patient as soon as they hear the ringing. A nurse regular call system is intended for routine communication between each patient and the nursing staff. Activation of the system at a patient's station will sound a repeating audible signal at the nurse station [1]. It should be noted that sometimes patients' requests are very criti$\mathrm{cal}$, and lack of attention to the smallest request can be hazardous or cause damages to the patient. This issue is vital for intensive care unit (ICU). Although the precise numbers of patient transfers to ICU are not available in the literature, one can assume that at least $15 \%$ of ICU patients are transported during a year [2]. On the other hand, Hospitalization in the ICU for patient and their family is a stressful phenomenon [3] and patient connection with ventilator increases this stress. Statistics show half of the ICU patients are treated with mechanical ventilation [4-6]. In the United States of America 1.5 million patients are under mechanical ventilation and hospitalized in ICU, and it has been shown that $55.5 \%$ of ICU 
patients survive [7]. People treated with mechanical ventilation or other devices are complete bed rest, and cannot move during treatment, due to these situations, they need call system more frequently. This need will increase when patient has tracheal tube or tracheostomy, and verbal communication is possible only after removing tracheal tube. Loss of communication is one of the most ICU patient's problems that causes a negative emotional sense of deprivation [4]. Difficulties in communication in ICU patients receiving mechanical ventilation are a source of stressful experiences and psychoemotional distress [8]. In such circumstances, the best way to solve problem is to use a device that can help patients to communicate. All nurse call systems are based on patients' speech but these patients cannot verbally communicate.

\section{MATERIAL AND METHOD}

This is intervention study that approved in Medical image \& Signal Processing Research Centre of Isfahan medical science. This survey designed and the device made to solve communication problems in ICU patient. It seems that the best design for "nurse call system" is horizontal panels. It has two parts include:

1) Hardware part: $1-$ LCD touch of a screen with the ability to rotate 360 degrees on the main body, 2-Pen smart for writing on the screen, 3 -one plat for put the system on it, 4- spring arm with the ability to change size for installation plat on wall near to the patient's bed.

2) Software part: we designed and programmed by Microsoft visual C\# express edition [9] that including: 1 -multi pages (1-symbol page (Figure 1), 2-typing page that concepts have been typed by patient in Persian or in English (Figure 2), 3- text page, in this page patient writes by the electronic pen), 2-vocal messages that have been related to each symbol, and 3-the system ability to be connect LAN systems and nursing stations.

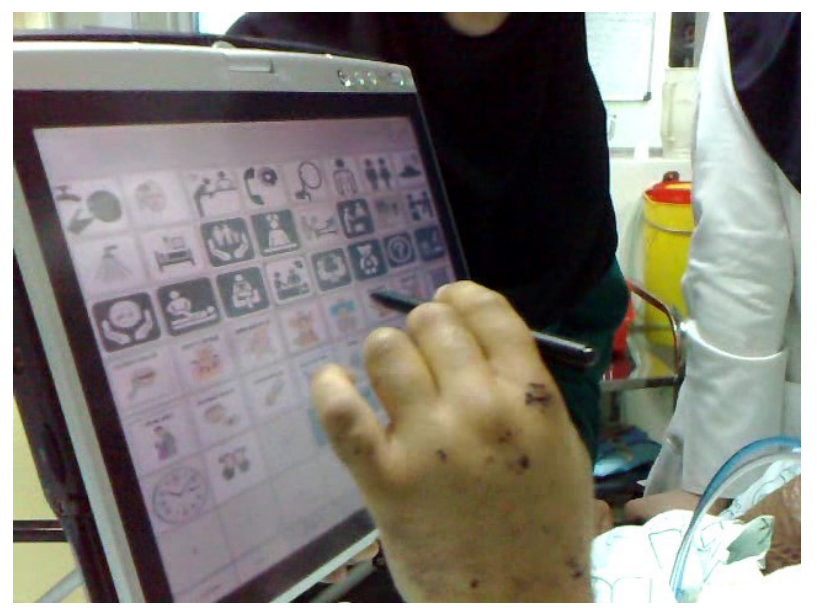

Figure 1. A sample of the patient's request using by symbols page.

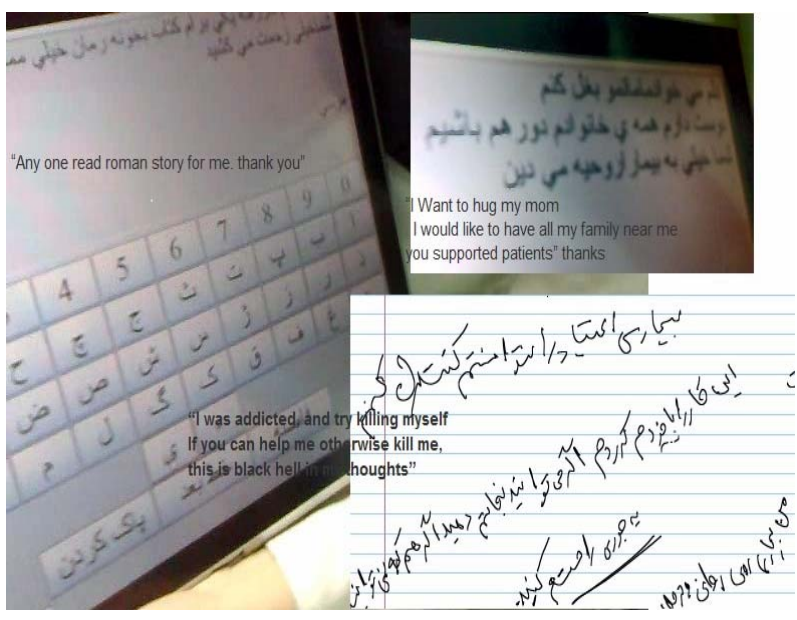

Figure 2. A sample of the patient's request using by typing page.

Table 1. Demographic characteristics of study population.

\begin{tabular}{cccc}
\hline Variable & $\mathrm{N}$ & $\%$ \\
\hline Male & 8 & 26.7 \\
Female & 22 & 73.3 \\
Nurse & 23 & 85.2 \\
physicians & 2 & 7.4 \\
nurse assistant & 2 & 7.4 \\
$21 \geq 29$ & 6 & 20.00 \\
$30 \geq 39$ & 11 & 36.67 \\
$40 \geq 50$ & 2 & 6.67 \\
Morning & 9 & 30.0 \\
Circulation & 18 & 60.0 \\
$1-4.9$ & 6 & 20.00 \\
$5-9.9$ & 12 & 40.00 \\
$>=10$ & 12 & 40.00 \\
\hline
\end{tabular}

We selected symbols from the most common Symbols that used in the health system in other previous studies $[10,11]$ and from experiences of nurses too. The system nurse call has applied in ICUs of Alzahra educational medical center. Patients and nurses participate in our study. Including criteria were alert patient and ability to work with device and ability to take the pen (for patients), have experience in ICU (for nurses) and correct device (for system). Research environments were central neurosurgical, trauma and surgery ICUs in educational medical center of Alzahra hospital. Survey were several stages (design, make, and test) and done in two groups (patient and nurses/physicians). Sampling was simple. Patients used device and completed questionnaire (we interviewed them after removed tracheal tube), and Nurses completed special questionnaires too.

Questionnaire contains 12 questions on five Likert 
scale options. The five scale that of a "totally agree $=5$ ", "agree $=4$ ", "no comment $=3$ ", "disagree= 2", "completely disagree $=1$ ". In addition questionnaire Categorized by five issues contain: 1) Fast awareness of patient status, 2) decrease patient anxiety and fell of security, 3) Improvement nurse communication with patient, 4) pay attention to patient problem \& solving problem, and 5) Selected appropriate symbols.

To determine the validity of content we used content validity index. In addition, we checked questionnaire reliability by check recheck. We took photos and video of the whole process when working with patients, and interviewed with patients, physicians and nurses, and distribute questioner. 40 cases (30 ICU personnel, 10 patients) answered questionnaires. For analysis data used SPSS version 8 and it analyzed in two groups (patients and staff nurses).

\section{RESULT}

Findings were design a new nurse call system for ICU patient, some pictures and videos from patients when using by nurse call system, and analysis questionnaires, that shown in nurse group were $26.7 \%$ (8) male and $73.3 \%$ (22) female, $75.6 \%$ (23) nurses, $6 \%$ (3) physicians, $7.6 \%$ (2) nurse assistant (Table 1). In group of patients were $60 \%$ male (6) and $40 \%$ (4) female. The frequency of scores giving by nurses and physicians' ideas showed that 28 of them $93.3 \%$ were "agree" or "completely agree" to the idea that using nurse call system due to "decrease patient anxiety and fell of security and about the other questions the nurse call system was accepted by more than 80 percent for majority of questions. Some statements such as "nurse call system attracts more attention" also "pay attention to patients problem \& solving problem" had the most score frequency (96.7\%). 100\% of ideas were "agree" and "completely agree" to the expression "Improvement nurse communication with patient". The most agree idea was related to "Fast awareness of patient status" (Table 2).

\section{DISCUSSION}

We did not find similar studies that worked on nurse call system for ICU patient, but the kinds of systems that like this study surveyed, and we compared them with our system. In one survey "wireless communication system" installed at St Agnes Hospital by Vocera Communications. This system enables connectivity between thirdpart systems as a nurse call system. The system decreased "average time a patient requests" about 51\% in all of observations. The results their study have shown that using communications system reduced overall mean time, especially when the needs were serious and urgent [12]. In addition, Ultra Phoenix is another nurse call system that uses a touch-screen computer. In this system, use acentral LCD and two-speakers or microphone (for situations that they do not want the speaker to use).

Another one system was "Intego Systems Inc" that in this system Patients contacted by a communication network with hospital nurses [13], and in other nurse call system reported two part including: I. Central monitor nurse call display; II. CMU-02 that it was wirelessly pieces, that patients to carry it. Patients can bring it, when necessary, and in this state patient situation will be determined in the nursing station, and Nurses can help patients [14]. Spetz and others wrote in their study, that risk of patient falls from bed is very important because it increases mortality and morbidity in hospital. In order to reduce these problems, they used system nurses call in Neurosurgery. Their system consists of two parts:

1) Antenna and a sensor installed near the patient had;

2) A bedside unit that was attached nurse call system. Their findings showed that rates of falling out of bed were reduced, and they reported about reduce cost-effectiveness in hospital [15].

The aim of our study was to design and build a system to help ICUs' patients, and other aim was patients communicate with others when they have intubation or tracheostomy tubes, but they are alert. We did not determined the rate of patient's falling or response time to request, but patient satisfaction evaluated, and the results showed that patient satisfaction increased by using nurse call system.

All of nurse call systems design by verbal, so patient must be able to talk with the nurse, but in this study

Table 2. Frequency distribution and score percent nurse call system according to personnel and patients' opinion.

\begin{tabular}{|c|c|c|c|c|c|c|c|c|}
\hline Participant & \multicolumn{4}{|c|}{ Personnel } & \multicolumn{4}{|c|}{ Patients } \\
\hline $\begin{array}{c}\text { Opinion } \\
\text { Fast awareness of patient status }\end{array}$ & \multicolumn{2}{|c|}{$\begin{array}{c}\text { Agree/completely } \\
\text { agree }\end{array}$} & \multicolumn{2}{|c|}{$\begin{array}{c}\text { Disagree/completel } \\
\text { y disagree }\end{array}$} & \multicolumn{2}{|c|}{$\begin{array}{c}\text { Agree/completely } \\
\text { agree }\end{array}$} & \multicolumn{2}{|c|}{$\begin{array}{c}\text { Disagree/completel } \\
\text { y disagree }\end{array}$} \\
\hline Decrease patient anxiety and fell of security & 28 & 93.3 & 2 & 0.7 & 10 & 100 & 0 & 0 \\
\hline Improvement nurse communication with patient & 30 & 100 & 0 & 0 & 10 & 100 & 0 & 0 \\
\hline Selected appropriate symbols & 24 & 82.8 & 6 & 17.2 & 9 & 90 & 1 & 10 \\
\hline
\end{tabular}


never need to speech verbally. The new design is based on symbols, and patient just select symbols by touch it or writ text communication by smart pen on display.

\section{CONCLUSIONS}

Nurse call system is solving many problems in intensive care unit patient, and increasing patients communication with nurses and physicians.

The Document patent number is $388,070,450$, and it is called "nurse call system" and registered in Iran patent Documents" on 18.07.1388

This article, resulted from research project No 188035 , is approved in Medical image and Signal Processing Research Centre Isfahan University of Medical Sciences and Health Services.

\section{ACKNOWLEDGEMENTS}

We thank the patients who took part in this study, and especial thanks from the Alzahra Educational medical Centre personal which help us in the investigation.

\section{REFERENCES}

[1] Nurse Call/Communication Systems (2013) D5034.MD The University of Texas, Anderson Cancer Center, ODG 121312, 1-9. http://www2.mdanderson.org/depts/cpm/standards/Guide s/D5034-M.pdf

[2] Wauer, H. and Wolf, S. (2008) Intrahospital transport of the ventilator-supported patient. In: Ventilation Clinical Applications and Pathophysiology, 355-364

[3] Chaboyera, W., Thalibb, L., Alcornc, K. and Fosterd, M. (2007) The effect of an ICU liaison nurse on patients and family's anxiety prior to transfer to the ward: An intervention study. Intensive and Critical Care Nursing, 23, 362-369. doi:10.1016/j.iccn.2007.04.005
[4] Hansen, F.H.J. (2000) Dyspenea in the ventilated patient: A call for patient-centered mechanical ventilation. Respiratory Care, 45, 1860-1446.

[5] Arabi, A., Tavakol, K.H. and Bhzadnzhad, M. (2005) Experiences of mechanical ventilation of patients. Nursing and Midwifery Research Journal, 30.

[6] Pour Ramezani, F. (2002) Survey of nursing care of patients how connected to Mechanical ventilator in critical care unit in Rasht educational hospital. Gilan Journal of Nursing, Gilan Medical University, 38, 22.

[7] Mojdeh, S., Sadri, A.R., Nabii, M., Emadian, H. and Rahimi, M. (2011) Designing the vocal alarm and improving medical ventilator. Iranian Journal of Nursing and Midwifery Research, 16, 26-33.

[8] Khalaila, R., Zbidat, W., Anwar, K., Bayya, A., Linton, D.M. and Sviri, S. (2011) Communication difficulties and psychoemotional distress in patients receiving mechanical ventilation. American Journal of Critical Care, 20, 470479. doi:10.4037/ajec2011989

[9] http://www.scopus.com/record/display.url?eid=2-s2.0-

[10] http://www.working-software.com/handbook/style/a364.h $\underline{\mathrm{tml}}$

[11] http://www.hablamosjuntos.org/signage/PDF/SymbolPost erB.pdf

[12] http://www.mayer-johnson-symbols.com/communication/ 02.htm

[13] Kuruzovich, J. (2008) Wireless communication role in patient response time: A study of vocera integration with a nurse calls system. Computers, Informatics, Nursing, 26, 159-166. doi:10.1097/01.NCN.0000304780.27070.ee

[14] Wireless Nurse Call System. http://www.easylinkuk.co.uk/page58.html

[15] Spetz, J., Jacobs, J. and Hatler, C. (2007) Cost effectiveness of a medical vigilance system to reduce patient falls, Nursing Economics, 25, 333-338, 352. 